\title{
FORMULATION AND EVALUATION OF FENOVERINE FLOATING TABLETS
}

\author{
RASHMITHA V, MADHUSUDAN RAO Y, PAVANI S*
}

Department of Pharmaceutics,Vaagdevi College of Pharmacy, Kakatiya University, Hanamkonda, Telangana, India. Email: pavanisrm@gmail.com

Received: 04 February 2021, Revised and Accepted: 15 March 2021

ABSTRACT

Objective: The purpose of this research was to develop a fenoverine gastroretentive drug delivery system which, following oral administration should have the ability to enhance and prolong the period of gastric residence time (GRD) with the desired in vitro release profile.

Methods: In the present study, fenoverine floating tablets were prepared using an effervescent method using sodium bicarbonate and citric acid as a gas-generating agent. The tablets were formulated using direct compression technology using xanthan gum and sodium alginate as polymers. Precompression powders were evaluated for angle of repose, bulk density, tapped density, Carr's index, and Hausner's ratio, and the prepared tablets were evaluated for weight variation, thickness, diameter, hardness, friability, drug content, floating lag time, total floating time, and in vitro dissolution studies. The formulations were optimized for the different concentrations of xanthan gum, sodium alginate, and their combinations.

Results: All the prepared formulations showed well in vitro buoyancy. The tablets remained buoyant for 6-12 h. The in vitro drug-release pattern of fenoverine floating tablets was adapted to different kinetic models with the highest regression to zero-order and Korsmeyer-Peppas, and the mechanism was found to be a Fickian mechanism.

Conclusion: Out of all the formulations prepared, in vitro dissolution studies of the F4 formulation were found to be maximum than other batches, which exhibited desired sustained release time followed by acceptable floating properties.

Keywords: Fenoverine, Gastric residence time, Effervescent method, Buoyancy, Floating properties.

(C) 2021 The Authors. Published by Innovare Academic Sciences Pvt Ltd. This is an open access article under the CC BY license (http://creativecommons.org/ licenses/by/4.0/) DOI: http://dx.doi.org/10.22159/ajpcr.2021v14i4.40999. Journal homepage: https://innovareacademics.in/journals/index.php/ajpcr

\section{INTRODUCTION}

The oral route is the most appropriate and widely used route for the delivery of drugs to the systemic circulation. This route has high acceptability for patients, particularly due to ease of administration. Over the years, oral dosage forms have become increasingly worldwise in the pharmaceutical field, with controlled release drug delivery (CRDDS) systems that release the drug at a predetermined, predictable, and controlled rate playing a major role [1]. The main imperative for the successful action of oral controlled drug delivery systems was to have good drug absorption throughout the gastrointestinal tract (GIT). The most preferable approach of oral controlled drug delivery is gastroretentive drug delivery system, where the dosage form can remain in the stomach for a prolonged period, thereby increasing the gastric residence time (GRT) and targeting site-specific drug release in the upper GIT for producing local or systemic effects. It is obtained by retaining the dosage form in the stomach and by releasing it in a controlled manner [2]. The following two parameters are optimized to develop sustainable orally controlled releasing drug delivery systems that deliver a drug for the required duration for optimal treatment at a therapeutically efficient range to a desirable place [3]. (a) Gastrointestinal transit modulation time: To modulate the transit time for GIT so that dosage form can be taken to or around the target absorption site and thus extend the time limit for maximizing the delivery of drugs. (b) Minimizing the elimination of the first hepatic pass: If the drug to be given undergoes extensive first-pass hepatic removal, preventive measures should be developed to either bypass or minimize the extent of hepatic metabolism. The purpose of the work is to develop drug delivery systems of fenoverine in which after oral administration should have the ability to prolong the gastric residence time with the desired in vitro release profile. Fenoverine is an antispasmodic drug used to relieve muscle spasm, cramps associated with the stomach, and abdominal pain associated with irritable bowel syndrome [4,5].
Due to the shorter half-life of Fenoverine (5-7 h) it requires frequent daily dosing and its therapeutic use in chronic conditions necessarily involves its formulation into a sustained release dosage form[6]. It is the most suitable drug to be formulated as a floating drug delivery system as it helps in increasing the gastric residence time and helps to have good control over the fluctuations in plasma drug concentration.

\section{MATERIALS AND METHODS}

\section{Materials}

Fenoverine was obtained as a gift sample from Euro drugs, sodium bicarbonate, xanthan gum, and sodium alginate obtained from Research-lab fine chem. Industries, citric acid from HiMedia laboratory, Talc from Sd fine-Chem Ltd, magnesium stearate from Qualikems Fine Chemicals Pvt. Ltd, and Lactose from Yarrow Chem products, all the ingredients, and reagents used were of analytical grade.

\section{Methods}

Pre-formulation studies

Pre-formulation studies are carried out to know and understand the physical and chemical behavior of a drug and also to know the drugexcipient compatibility using FTIR.

\section{Solubility studies}

Solubility was determined by weighing accurately $1 \mathrm{~g}$ of the drug and transferring it into 5 different $10 \mathrm{ml}$ volumetric flasks containing different solvents (water, ethanol, methanol, DCM, and $0.1 \mathrm{~N} \mathrm{HCl}$ ), respectively [6].

\section{FTIR studies}

It is often used to identify organic, inorganic, and polymeric materials present in the dosage form, analyse pure drug formulations, polymer, and drug-loaded polymer formulations, as well as functional group 
determination. The spectra were scanned at ambient temperature over the wave-number range of $3600-400 \mathrm{~cm}^{2}[7,8]$.

\section{Micromeritic properties of powder blend [9-11] \\ Angle of repose}

It is a maximum angle between the surface of a pile of powder and its horizontal plane. It is determined by pouring the powder to flow through a funnel and fall freely onto the surface. Then, the height and diameter of the resulting cone are measured using the following equation. Tan $\theta=h / r$, where, $\theta$ is the angle of repose, $h=$ height of the pile, and $\mathrm{r}=$ radius of the pile.

\section{Bulk density and tapped density}

A known amount of powder blend was taken from each formula and introduced into a $10 \mathrm{ml}$ measuring cylinder and shaken lightly to break up the agglomerates. After measuring, the initial volume of the powder bulk density was calculated using the following formula.

Bulk density $=$ (weight of the powder) / (bulk volume of the powder)

The cylinder containing the sample was tapped using a mechanical tapped density tester (Electrolab) that provides a fixed drop of $14 \pm 2$ $\mathrm{mm}$ at a nominal rate. The cylinder tapping was continued until no further change in the volume was noted. The tapped density was calculated using the following formula.

Tapped density $=$ (weight of the powder) $/$ (tapped volume)

Compressibility index and Hausner's ratio

They were measured using the following formula.

$$
\text { Carr's index }=\frac{\text { Tapped density }- \text { Bulk density } \times 100}{\text { Tapped density }}
$$

Hausner's ratio $=$ Tapped density $/$ Bulk density

\section{Analytical method for calibration curve of fenoverine}

The maximum wavelength of fenoverine was measured using UV-visible spectroscopy which was found to be $261 \mathrm{~nm}$. The secondary stock solution $(100 \mu \mathrm{g} / \mathrm{ml})$ was prepared from the primary stock solution $(1 \mathrm{mg} / \mathrm{ml})$ with $0.1 \mathrm{~N} \mathrm{HCl}$ as a buffer. Further dilutions were made from the secondary stock solution to obtain $2-10 \mu \mathrm{g} / \mathrm{ml}$. The absorbance of each aliquot was measured at $261 \mathrm{~nm}$ against $0.1 \mathrm{~N} \mathrm{HCl}$ as blank. Then, a graph of concentration of drug versus absorbance was plotted by applying linear regression analysis [8]. The standard regression equation obtained for fenoverine was $y=0.054 x+0.013$ with a coefficient of regression $\left(R^{2}\right)$ of 0.997 .

\section{Formulation of floating tablets}

The required amount of the ingredients was weighed as per the composition mentioned in Tables 1 and 2, followed by sieving and blending. All the pre-compression parameters were studied and finally compressed into tablets by direct compression method using a rotary tablet machine at specific pressure using $8 \mathrm{~mm}$ round punches, and the weight of the tablet was compressed to $200 \mathrm{mg}$.

\section{Post-compression characterization}

\section{Weight variation}

It is determined by taking 20 tablets randomly from each formulation and weighing them individually using an electronic balance, and the average weight was calculated which was compared with an individual weight of the tablet. The deviation for any two tablets should not exceed more than the average weight [12-14].

\section{Hardness and thickness}

Hardness is the ability of the tablet to withstand mechanical shocks during handling. It is determined by the Monsanto hardness tester by randomly selecting three tablets from each formulation, which is measured in terms of $\mathrm{kg} / \mathrm{cm}^{2}$ [13]. The thickness of the tablet was determined randomly by selecting three tablets from each formulation using vernier calipers which were expressed in $\mathrm{mm}$. The extent of deviation in the tablet formulation should not exceed the limit of $\pm 5 \%$ of their determined values.

\section{Friability}

It is used to determine the physical strength of uncoated tablets upon exposure to mechanical shock and attrition with the help of Roche friabilator, which is expressed in terms of percentage. In this, ten tablets were weighed and placed in the friabilator and operated at $25 \mathrm{rpm}$ for about 4 min (100 revolutions) [15]. Then, the tablets were dedusted and reweighed. The friability was calculated using the following equation.

$$
\text { Friability }=\frac{\text { Initial weight }- \text { Final weight } \times 100}{\text { Initial weight }}
$$

Drug content

Ten tablets were taken and placed in a mortar and crushed into a fine powder. An accurately weighed powder equivalent to $100 \mathrm{mg}$ of fenoverine was transferred into a $100 \mathrm{ml}$ volumetric flask containing $100 \mathrm{ml}$ of $0.1 \mathrm{~N} \mathrm{HCl}$, and the absorbance was measured against blank at $261 \mathrm{~nm}$.

\section{In vitro buoyancy studies}

The in vitro buoyancy was determined by finding the floating lag time (FLT) and total floating time (TFT). This is carried out by placing the tablet in a $100 \mathrm{ml}$ beaker containing $0.1 \mathrm{~N} \mathrm{HCl} \mathrm{[16].} \mathrm{The} \mathrm{time} \mathrm{required}$ for the tablet to rise from the bottom of the beaker to the surface and float was measured as FLT and the duration of the tablet that constantly floats on the dissolution medium was noted as TFT.

In vitro dissolution studies

It was performed using USP Type I (basket) dissolution apparatus at a rotational speed of $50 \mathrm{rpm}$. The dissolution medium consists of $900 \mathrm{ml}$ of $0.1 \mathrm{~N} \mathrm{HCl}$, maintained at a temperature of $37 \pm 0.5^{\circ} \mathrm{C}$ [16]. At predetermined time intervals, a $5 \mathrm{ml}$ sample was withdrawn from the dissolution apparatus and replaced with a fresh dissolution medium. The collected samples were filtered through a $0.45 \mu \mathrm{m}$ membrane filter and diluted if necessary with $0.1 \mathrm{~N} \mathrm{HCl}$. The absorbance of these

Table 1: Composition of fenoverine floating tablets containing xanthan gum or sodium alginate

\begin{tabular}{lllllllll}
\hline Ingredients (mg) & F1 & F2 & F3 & F4 & F5 & F6 & F7 & F8 \\
\hline Fenoverine & 100 & 100 & 100 & 100 & 100 & 100 & 100 & 100 \\
Xanthan Gum & 30 & 35 & 40 & 45 & - & - & - & - \\
Sodium alginate & - & - & - & - & 30 & 35 & 40 & 45 \\
Sodium bicarbonate & 30 & 30 & 30 & 30 & 30 & 30 & 30 & 30 \\
Citric acid & 15 & 15 & 15 & 15 & 15 & 15 & 15 & 15 \\
Magnesium stearate & 1.5 & 1.5 & 1.5 & 1.5 & 1.5 & 1.5 & 1.5 & 1.5 \\
Talc & 1.5 & 1.5 & 1.5 & 1.5 & 1.5 & 1.5 & 1.5 & 1.5 \\
Lactose & 22 & 17 & 12 & 7 & 22 & 17 & 12 & 7 \\
\hline
\end{tabular}

Table 2: Composition of fenoverine floating tablets containing a combination of polymers (xanthan gum and sodium alginate)

\begin{tabular}{llllllll}
\hline Ingredients (mg) & F9 & F10 & F11 & F12 & F13 & F14 & F15 \\
\hline Fenoverine & 100 & 100 & 100 & 100 & 100 & 100 & 100 \\
Xanthan Gum & 15 & 20 & 15 & 30 & 15 & 30 & 10 \\
Sodium alginate & 15 & 15 & 20 & 15 & 30 & 10 & 30 \\
Sodium bicarbonate & 30 & 30 & 30 & 30 & 30 & 30 & 30 \\
Citric acid & 15 & 15 & 15 & 15 & 15 & 15 & 15 \\
Magnesium stearate & 1.5 & 1.5 & 1.5 & 1.5 & 1.5 & 1.5 & 1.5 \\
Talc & 1.5 & 1.5 & 1.5 & 1.5 & 1.5 & 1.5 & 1.5 \\
Lactose & 22 & 17 & 17 & 7 & 7 & 12 & 12 \\
\hline
\end{tabular}


solutions was measured at $261 \mathrm{~nm}$. The cumulative percentage of drug release was calculated using the equation obtained from a calibration curve.

\section{Kinetic analysis of drug release data}

Several different kinetic models will describe the total release of drugs from dosage forms [17]. As qualitative and quantitative changes in the formulation may alter the release of drugs and the performance of in vivo, it is always desirable to develop tools that facilitate the development of the product by reducing the need for biostudies. In this regard, the use of data on in vitro drug dissolution to predict in vivo bioperformance can be considered as a rational development of controlled release formulations. The method of approaches used to examine the kinetics of drug release from controlled release formulation is model dependent methods (zero order, first order, Higuchi, Korsmeyer-Peppas, etc.) [18].

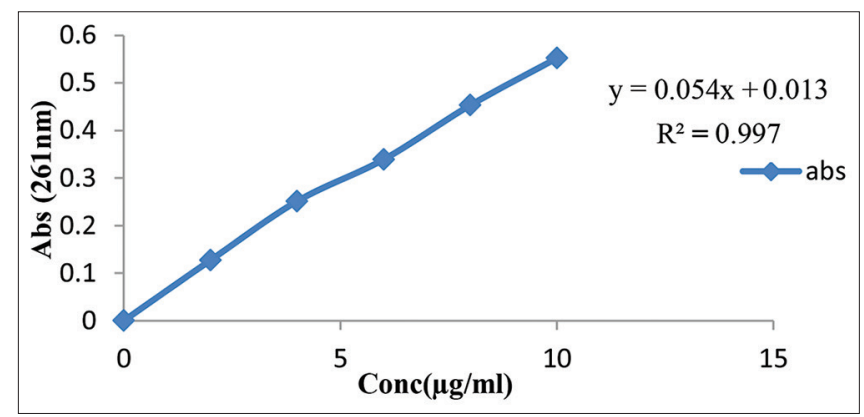

Fig. 1: Standard curve of fenoverine at $\lambda \max 261 \mathrm{~nm}$

\section{RESULTS AND DISCUSSION}

Fenoverine floating tablets were prepared by direct compression method. Various evaluation parameters were measured. From the solubility studies, it was found that fenoverine was practically insoluble in water and DCM, slightly soluble in ethanol, methanol, and freely soluble in $0.1 \mathrm{~N} \mathrm{HCl}$. A standard calibration curve for fenoverine was acquired by measuring the absorbance at $261 \mathrm{~nm}$ in $0.1 \mathrm{~N} \mathrm{HCl}$ and by plotting the graph of absorbance against concentration. The standard plot of fenoverine was shown in Fig. 1.

\section{Pre-formulation parameters}

From the FTIR studies, it was observed that all the major peaks of fenoverine remained the same and compatible with excipients used in the study. Parameters such as the angle of repose, bulk density, tapped density, Carr's index, and Hausner's ratio were evaluated to determine the flow properties of the prepared powder mixture [19-21]. The results of the pre-compression parameters are shown in Table 3. The angle of repose and compressibility index for all the formulations were found to be in the range that indicated good flow properties and hence were suitable for compression into floating tablets.

The quantitative evaluation and assessment of a tablet's chemical, physical, and bioavailability properties are important in the design of a tablet and to monitor product quality. These properties are important since chemical breakdown or interactions between tablet components may alter the physical tablet properties and greatly affect the bioavailability of the tablet system. There are various standards that have been set in the various pharmacopeia. These include the diameter, size, shape, thickness, weight, hardness, disintegration, and dissolution

Table 3: Pre-compression characterization of the powder blend

\begin{tabular}{|c|c|c|c|c|c|}
\hline Formulation & Carr's index (\%) & Bulk density (g/cc) & Tapped density (g/cc) & Angle of repose $(\theta)$ & Hausner's ratio \\
\hline F1 & $21.7 \pm 0.65$ & $0.47 \pm 0.06$ & $0.62 \pm 0.09$ & $28.9 \pm 0.52$ & $1.06 \pm 0.05$ \\
\hline $\mathrm{F} 2$ & $22.7 \pm 0.55$ & $0.48 \pm 0.09$ & $0.64 \pm 0.04$ & $27.7 \pm 0.36$ & $1.16 \pm 0.26$ \\
\hline F3 & 23.40 .62 & 0.490 .05 & $0.61 \pm 0.06$ & $28.9 \pm 0.52$ & $1.18 \pm 0.03$ \\
\hline F4 & $24.6 \pm 1.21$ & $0.50 \pm 0.07$ & $0.65 \pm 0.04$ & $29.9 \pm 0.51$ & $1.17 \pm 0.06$ \\
\hline F5 & $21.2 \pm 0.02$ & $0.48 \pm 0.13$ & $0.59 \pm 0.05$ & $27.6 \pm 0.42$ & $1.14 \pm 0.03$ \\
\hline F6 & $21.6 \pm 0.37$ & $0.50 \pm 0.02$ & $0.60 \pm 0.02$ & $28.2 \pm 0.23$ & $1.14 \pm 0.16$ \\
\hline F7 & $22.5 \pm 0.46$ & $0.49 \pm 0.06$ & $0.61 \pm 0.06$ & $28.6 \pm 0.50$ & $1.15 \pm 0.05$ \\
\hline F9 & $23.7 \pm 0.59$ & $0.51 \pm 0.02$ & $0.58 \pm 0.02$ & $26.5 \pm 0.38$ & $1.13 \pm 0.27$ \\
\hline F10 & $24.2 \pm 0.09$ & $0.49 \pm 0.12$ & $0.62 \pm 0.05$ & $28.6 \pm 0.54$ & $1.16 \pm 0.02$ \\
\hline F11 & $23.5 \pm 0.04$ & $0.48 \pm 0.06$ & $0.61 \pm 0.08$ & $29.1 \pm 0.42$ & $1.14 \pm 0.22$ \\
\hline F12 & $23.9 \pm 0.58$ & $0.48 \pm 0.19$ & $0.59 \pm 0.06$ & $28.4 \pm 0.50$ & $1.07 \pm 0.03$ \\
\hline F13 & $22.3 \pm 0.72$ & $0.50 \pm 0.03$ & $0.62 \pm 0.03$ & $27.6 \pm 0.49$ & $1.14 \pm 0.25$ \\
\hline F14 & $23.6 \pm 0.22$ & $0.47 \pm 0.07$ & $0.64 \pm 0.03$ & $28.4 \pm 0.52$ & $1.17 \pm 0.02$ \\
\hline F15 & $24.2 \pm 0.52$ & $0.48 \pm 0.09$ & $0.62 \pm 0.06$ & $28.9 \pm 0.47$ & $1.16 \pm 0.06$ \\
\hline
\end{tabular}

Table 4: Physicochemical evaluation parameters of fenoverine tablets

\begin{tabular}{|c|c|c|c|c|c|}
\hline Formulation & Weight variation (mg) & Hardness $\left(\mathrm{kg} / \mathrm{cm}^{2}\right)$ & Thickness (mm) & Friability (\%) & Drug content (\%) \\
\hline F1 & $195.4 \pm 0.40$ & $4.2 \pm 0.32$ & $3.2 \pm 0.16$ & $0.27 \pm 0.06$ & $96.32 \pm 1.2$ \\
\hline F2 & $196.2 \pm 0.68$ & $4.3 \pm 0.73$ & $3.1 \pm 0.22$ & $0.25 \pm 0.01$ & $97.36 \pm 1.4$ \\
\hline F3 & $198.6 \pm 1.40$ & $4.4 \pm 0.34$ & $3.1 \pm 0.38$ & $0.23 \pm 0.04$ & $96.69 \pm 1.2$ \\
\hline $\mathrm{F} 4$ & $199.6 \pm 0.38$ & $4.5 \pm 0.84$ & $3.4 \pm 0.16$ & $0.21 \pm 0.02$ & $99.89 \pm 1.6$ \\
\hline F5 & $194.6 \pm 0.38$ & $4.3 \pm 0.62$ & $3.3 \pm 0.14$ & $0.20 \pm 0.04$ & $95.33 \pm 1.4$ \\
\hline F6 & $196.7 \pm 1.21$ & $4.3 \pm 0.64$ & $3.1 \pm 0.15$ & $0.27 \pm 0.02$ & $96.69 \pm 1.3$ \\
\hline F7 & $196.6 \pm 0.92$ & $4.3 \pm 0.32$ & $3.2 \pm 0.12$ & $0.22 \pm 0.06$ & $96.97 \pm 1.3$ \\
\hline F9 & $195.6 \pm 0.90$ & $4.0 \pm 0.40$ & $3 \pm 0.18$ & $0.26 \pm 0.04$ & $92.21 \pm 1.1$ \\
\hline F10 & $197.1 \pm 1.40$ & $4.4 \pm 0.52$ & $3.1 \pm 0.16$ & $0.24 \pm 0.02$ & $94.32 \pm 1.3$ \\
\hline F11 & $197.2 \pm 0.48$ & $4.6 \pm 0.64$ & $3.1 \pm 0.14$ & $0.24 \pm 0.06$ & $95.12 \pm 1.4$ \\
\hline F12 & $198.5 \pm 0.55$ & $4.5 \pm 0.32$ & $3.2 \pm 0.12$ & $0.25 \pm 0.05$ & $97.18 \pm 1.6$ \\
\hline F13 & $198.4 \pm 0.91$ & $4.3 \pm 0.34$ & $3.4 \pm 0.02$ & $0.23 \pm 0.04$ & $93.55 \pm 1.2$ \\
\hline F14 & $196.4 \pm 0.64$ & $4.2 \pm 0.24$ & $3.3 \pm 0.12$ & $0.27 \pm 0.04$ & $94.33 \pm 1.3$ \\
\hline F15 & $199.2 \pm 0.90$ & $4.5 \pm 0.21$ & $3.3 \pm 0.18$ & $0.19 \pm 0.06$ & $98.18 \pm 1.4$ \\
\hline
\end{tabular}


character [22-24]. The diameter and shape depend upon the die and punches selected for the compression of tablets. The results of the physicochemical properties of tablets prepared are shown in Table 4. The results showed uniformity in weight and thickness of the tablets. The results also revealed that the tablets would not break during handling and transportation and maintain integrity throughout the storage.
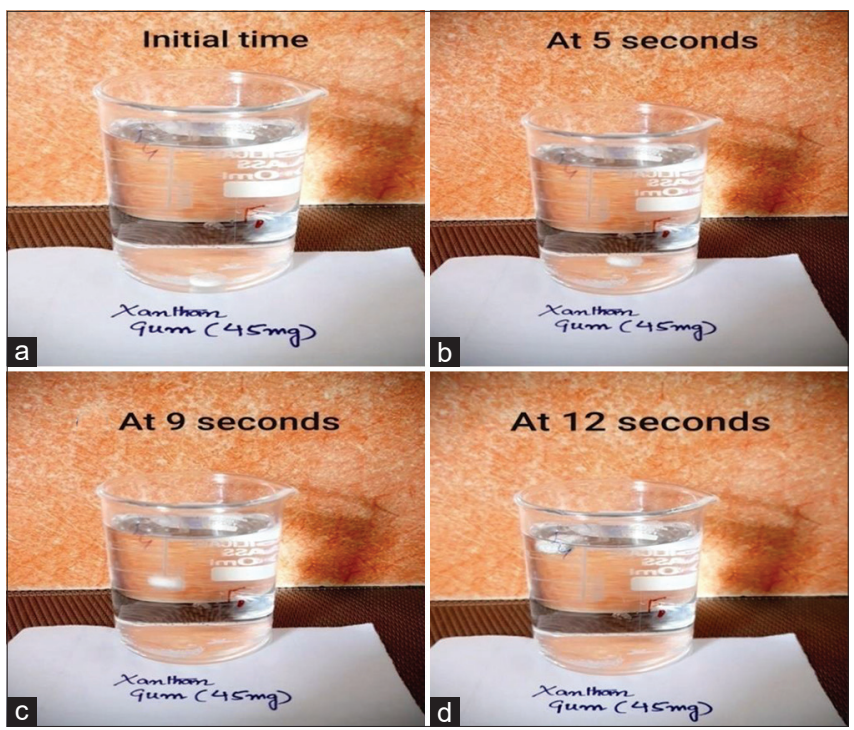

Fig. 2: Pictorial representation of buoyancy of floating tablet (F4)

\section{In vitro buoyancy studies}

The in vitro buoyancy studies in $0.1 \mathrm{~N} \mathrm{HCl}$ revealed good buoyancy for all the formulations, where the buoyancy lag time was found to be $<20 \mathrm{~s}$ (Table 5). Sodium bicarbonate and citric acid were used as effervescent agents. Upon contact with an acidic medium, the fluid permeates into the tablet, which generates $\mathrm{CO}_{2}$. The gas generated is trapped and protected within the gel, formed by the hydration of polymer, thereby lowering the density of the tablet below $1 \mathrm{~g} / \mathrm{cm}^{3}$, where the tablet becomes buoyant to float.

In the present study, fenoverine was formulated into a controlled release floating tablet. The preliminary studies indicate that the tablet containing fenoverine alone could not maintain the integrity of the tablet up to $12 \mathrm{~h}$ where it disintegrated completely after $6 \mathrm{~h}$, and rapid erosion was observed when placed in the dissolution medium because of its low viscosity. Hence, this can be overcome by combining the fenoverine with xanthan gum and sodium alginate as polymers which controlled the release of drugs and help in maintaining the tablet integrity [25-28]. From the present study, it was observed that the formulations containing xanthan gum as polymer have increased the viscosity of tablets in the dissolution medium and shown prolonged drug release for about $12 \mathrm{~h}$ (Fig. 2).

\section{In vitro drug release studies}

Drug release from fenoverine floating tablets was studied for about $12 \mathrm{~h}$ in $0.1 \mathrm{~N} \mathrm{HCl}$ as shown in Figs. 3-5. Total 15 formulations were prepared, where the first four F1-F4 formulations contain xanthan gum as polymer, F5-F8 contain sodium alginate as polymer, and F9-F15 contains a combination of xanthan gum and sodium alginate. Polymers were used in concentrations of $30 \%, 35 \%, 40 \%$, and $45 \%$. The release of fenoverine from the tablets is dependent on the percentage of release retardant contained within the tablet.

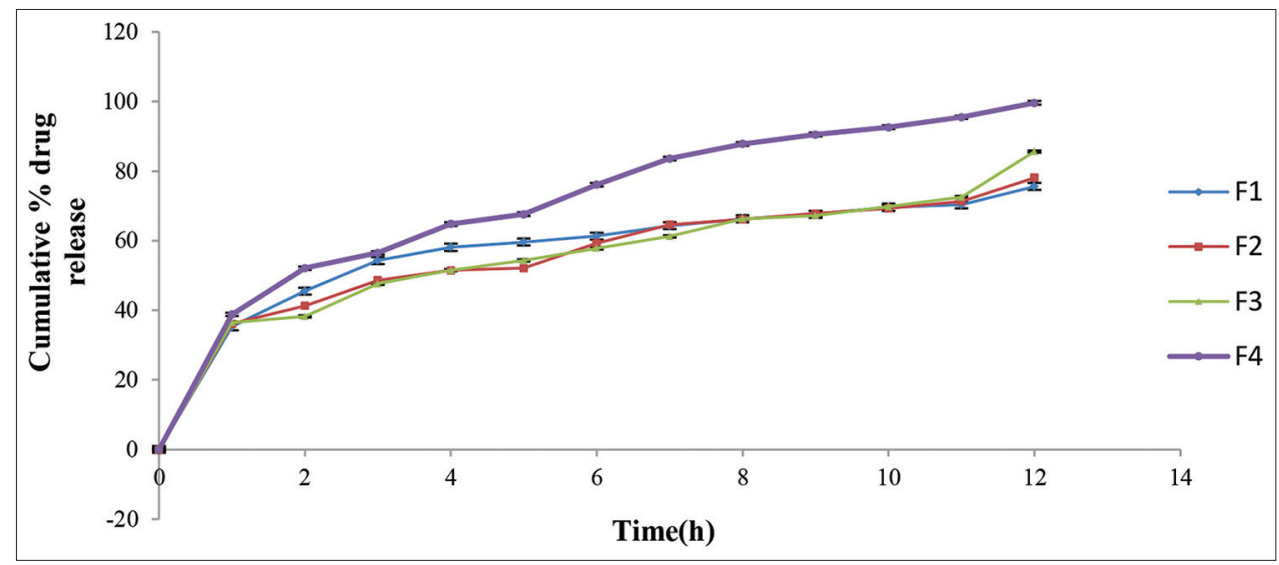

Fig. 3: Graphical representation of drug release of F1-F4 containing xanthan gum

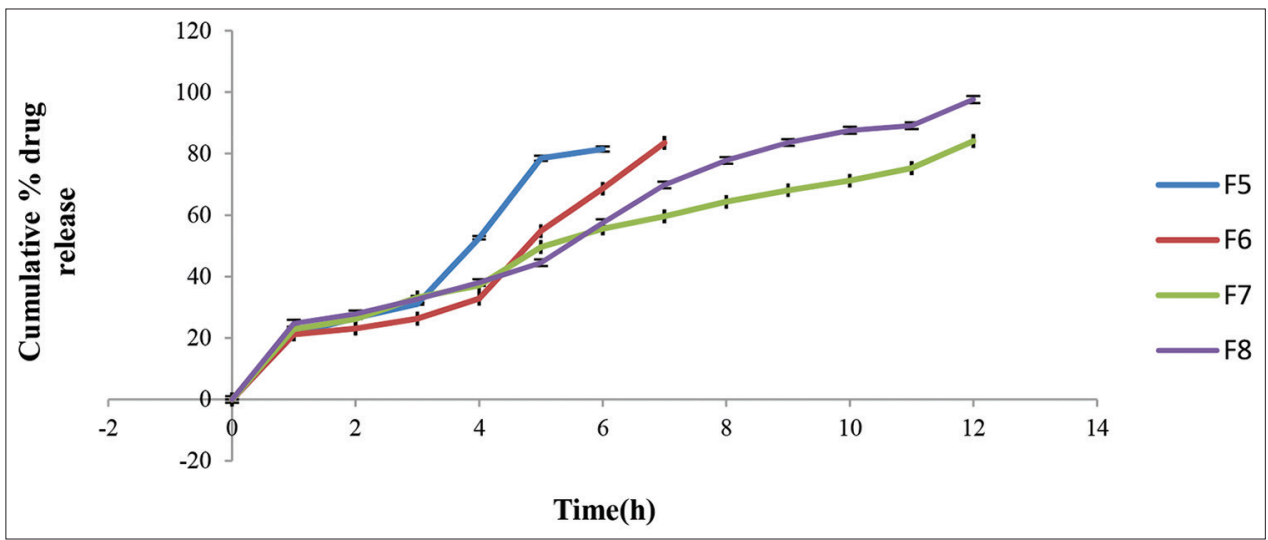

Fig. 4: Graphical representation of \% drug release of F5-F8 containing sodium alginate 


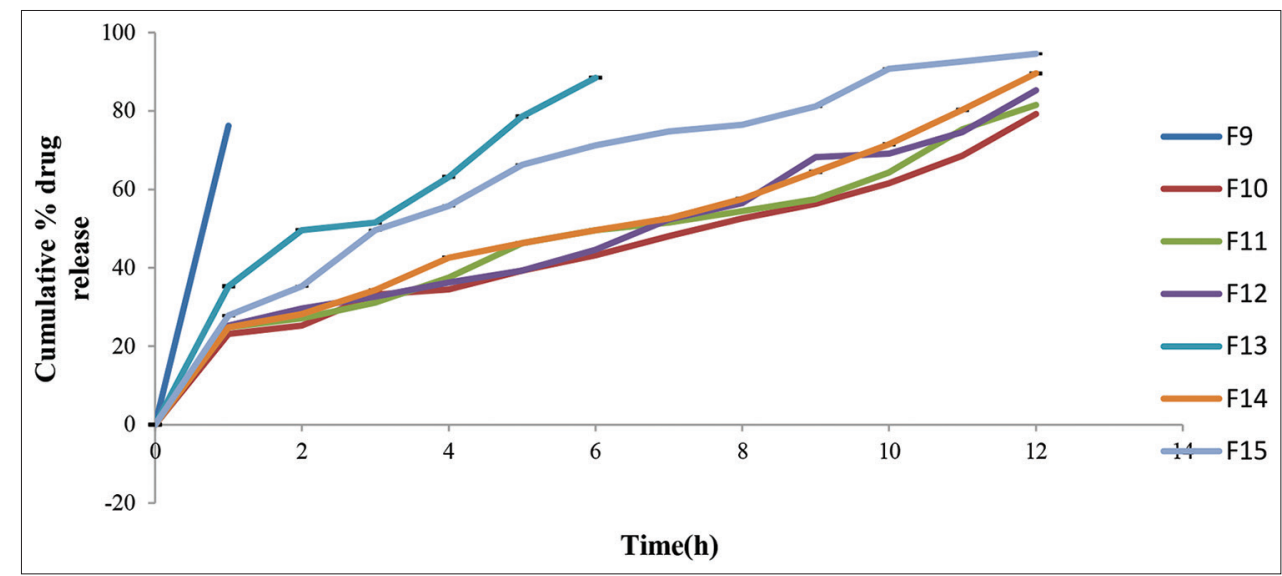

Fig. 5: Graphical representation of \% drug release of F9-F15

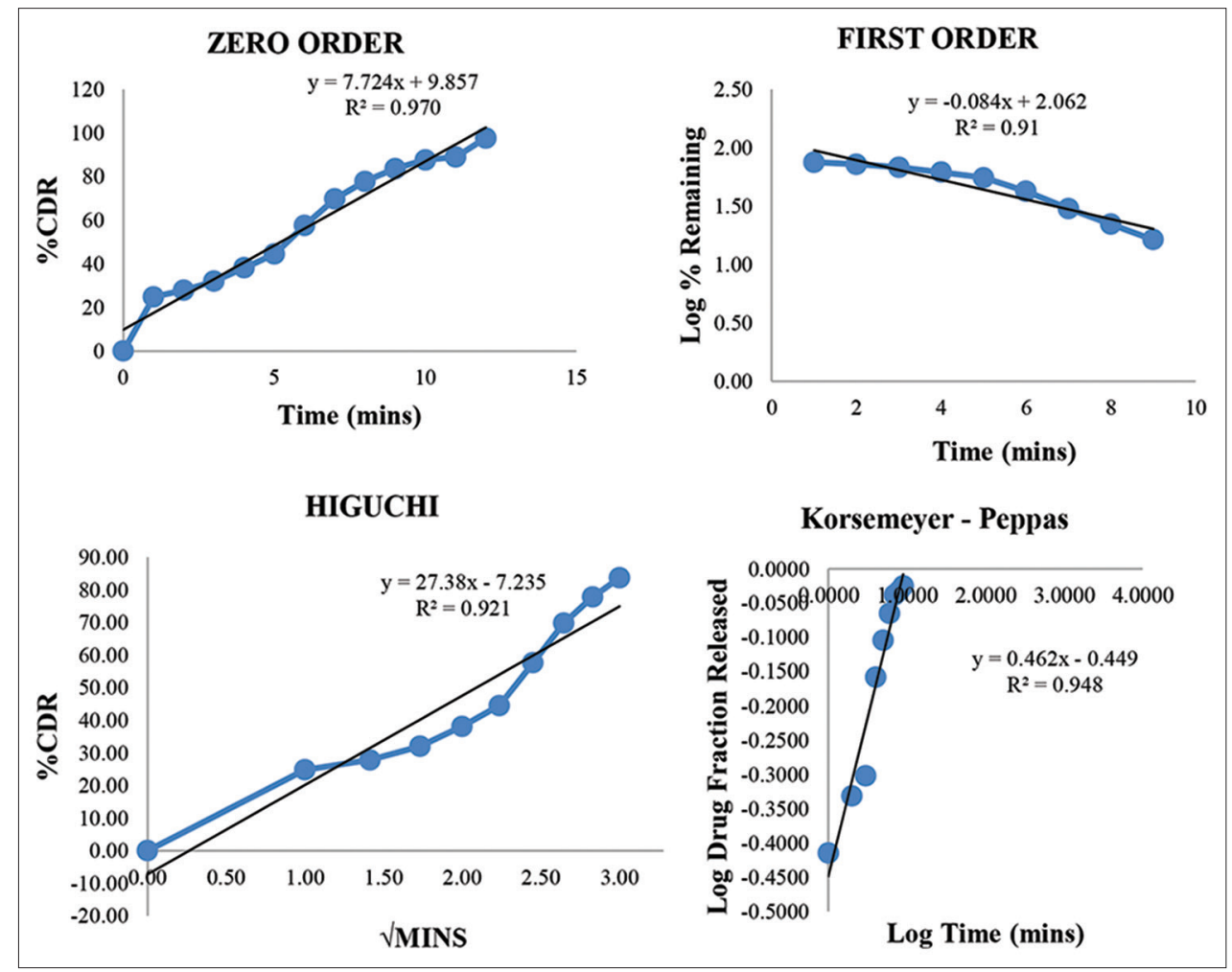

Fig. 6: Release kinetic models of optimized formulation (F4)

Table 5: Floating properties of prepared tablets

\begin{tabular}{lll}
\hline Formulation code & Floating lag time (s) & Total floating time (h) \\
\hline F1 & 14 & $\geq 12$ \\
F2 & 14 & $\geq 12$ \\
F3 & 13 & $\geq 12$ \\
F4 & 12 & $\geq 12$ \\
F5 & 14 & 6 \\
F6 & 16 & 12 \\
F7 & 16 & $\geq 12$ \\
F8 & 15 & Dispersed \\
F9 & - & $\geq 12$ \\
F10 & 14 & $\geq 12$ \\
F11 & 15 & 6 \\
F12 & 13 & $\geq 12$ \\
F13 & 13 & $\geq 12$ \\
F14 & 19 & \\
F15 & 17 &
\end{tabular}

It was observed that as the percentage of the polymer was increased, the drug release from the tablet decreased. Upon comparison of both the polymers, xanthan gum has shown better control of drug release from the tablet up to $12 \mathrm{~h}$ because of its higher molecular weight, high swelling rate, gel consistency, and sustained release behavior. The results have shown that xanthan gum has a greater drug retarding ability. Among the formulations containing xanthan gum (F1-F4), F4 has shown greater drug release for a relatively prolonged period.

The drug release data of fenoverine floating tablets were fitted into various mathematical models (zero order, first order, Higuchi, Korsmeyer-Peppas) [29,30] given Fig. 6 to evaluate the kinetics and mechanism of drug release. The model that gives a high $\mathrm{R}^{2}$ value is considered the best fit for the release data.

\section{CONCLUSION}

Fenoverine floating tablets were prepared using xanthan gum and sodium alginate as polymers in optimized concentrations by the direct compression method. The results of the present study indicate that the tablets containing fenoverine alone cannot control its release effectively for $12 \mathrm{~h}$, where this problem is overcome by combining the drug with 
polymers such as xanthan gum and sodium alginate, which helped in increasing the viscosity of the formulation in the dissolution medium and thereby prolonging the drug release effectively for $12 \mathrm{~h}$. Among various formulations, the F4 formulation containing $45 \%$ of xanthan gum was considered as the best formulation based on the drug release pattern, where it has shown $99.6 \%$ of drug release at the end of $12 \mathrm{~h}$. From the present study, it was concluded that the formulation F4 has shown better swelling properties with desired drug release kinetics, which especially follows zero-order release and floating behavior.

\section{ACKNOWLEDGMENT}

The authors are thankful to the management of Vaagdevi College of Pharmacy, for providing the necessary facilities and materials to carry out this work

\section{AUTHORS CONTRIBUTIONS}

All the authors contributed to the preparation of the final manuscript.

\section{CONFLICTS OF INTEREST}

There are no conflicts of interest regarding the publication of this article to disclose.

\section{AUTHORS FUNDING}

The authors did not receive any funding for this research work.

\section{REFERENCES}

1. Gadge G. Gastroretentive floating drug delivery system: An Overview. Res J Pharm Dosage Forms Technol 2020;12:213-26.

2. Jigar V, Jai M. Development and optimization of floating tablets containing rebamipide. Res J Pharm Dosage Forms Technol 2020;12:7-12.

3. Santosh Kumar R. An update on gastroretentive floating systems. World J Pharm Pharm Sci 2016;5:476-525.

4. Ajit K, Trushali M. Application of novel natural polymers for controlling the release of fenoverine from controlled release matrix tablets. Int $\mathrm{J}$ Appl Pharm 2017;9:1-9.

5. Sunil Kumar B, Madhusudan RY. Formulation and evaluation of rapidly disintegrating fenoverine tablets: Effect of superdisintegrants. Drug Dev Ind Pharm 2007;33:1225-32.

6. Jagdish R, Rahul S. In vitro characterization of floating drug delivery system of Ketoconazole. J Drug Deliv Ther 2019;9:22-9.

7. Sudke SG, Madhusudan RY. Formulation and release behaviour of sustain release fenoverine HPMC matrix tablets. Int J Univ Pharm Bio Sci 2013;2:2319-8141.

8. Dipesh P, Sunil Kumar S. Controlled-release effervescent floating tablet of verpamil hydrochloride: Development and optimization. J Pharm Sci Res 2016;8:732-40.

9. Chinna EM, Jaya S. Design and in vitro characterization of floating tablets of metronidazole. Asian J Pharm Clin Res 2019;12:539-44.
10. Abhishek C, Kapil C. Floating drug delivery systems: A better approach. Int Curr Pharm J 2012;1:110-8.

11. Kharia AA, Singhai AK. Design and optimization of floating drug delivery system of Acyclovir. Indian J Pharm Sci 2010;72:599-606.

12. Sanjay D, Snigdha D. Formulation and evaluation of floating matrix tablet of atenolol for gastro-retentive drug delivery. Int J Pharm Pharm Sci 2012;4:433-7.

13. Zilpha M, Pavani S, Ashish S. Formulation and taste masking of metronidazole oral disintegrating tablets by novel approach. Int J Pharm Qual 2020;11:399-403.

14. Pavani S, Sushma M. Formulation and evaluation of lamivudine floating tablets by sublimation method. Am J PharmTech Res 2020;10:1-9.

15. Ramdas T, Madhuraj S. Formulation and evaluation of gastro retentive floating tablets of lafutidine. J Drug Deliv Ther 2018;8:393-9.

16. Natasha TC. Formulation and Evaluation of Controlled release floating tablets of Cefixime using Hydrophilic polymers. Int Res J Pharm 2019;10:2230-8407.

17. Chokshi G. Formulation and evaluation of gastro-retentive floating tablets of ciprofloxacin hydrochloride. Int $\mathrm{J}$ Pharm Pharm Sci 2016;8:148-52.

18. Sriram P, Deepak K, Sujitha H. Preparation and in vitro evaluation of chitosan microspheres of eplerenone. Int $\mathrm{J}$ Pharm Pharm Sci 2013;5:226-9.

19. Pakhale NV, Gondkar SB. Formulation development and evaluation of fluoxetine effervescent floating tablets. J Drug Deliv Ther 2019;9:358-66.

20. Lavanya M, Chinna EM. Design, development and in vitro characterization of floating tablets of propranolol hydrochloride. Res J Pharm Dosage Forms Technol 2020;13:5088-94.

21. Sushma M, Pavani S. Formulation and evaluation of lamivudine floating tablets by sublimation method. Am J PharmTech Res 2020;10:141-9.

22. Nagaramya $\mathrm{CH}$, Pavani S, Shravan Y. Formulation and evaluation of colon drug delivery of metronidazole mini-tablets. World J Pharm Res 2020;9:1639-59.

23. Saritha D, Ganesh Kumar Y. Formulation design, development of gastro retentive floating tablets of propranolol. Asian J Pharm 2018;12:747-51.

24. Taraka RC, Bhavyasri K. Formulation and evaluation of zidovudine floating tablets. World J Pharm Pharm Sci 2018;7:1210-20.

25. Kulkarni GS, Prabhansh P. Formulation and evaluation of sustained release floating tablets of an antihypertensive diltiazem. Int J Pharm Sci Nanotechnol 2017; 10:3844-52.

26. Bakhle SS, Gulkari VD. Development and evaluation of ofloxacin floating tablets using natural polymers: Sterculia foetida linn. gum. Int J Pharm Pharm Sci 2016;8:356-60.

27. Wadher KJ. Formulation, and evaluation of gastro-retentive floating tablets using carbopol with xanthan gum and guar gum. Int J ChemTech Res 2017;10:300-8.

28. Rabia A, Yasir M. Techniques and polymers used to design gastroretentive drug delivery systems- a review. World J Pharm Pharm Sci 2014;3:97-110.

29. Pavani S, Deepak K. Preparation and in vitro evaluation of chitosan microspheres of eplerenone. Int J Pharm Pharm Sci 2013;5:226-9.

30. Laila H, Nadia M. Preparation and evaluation of metronidazole sustained release floating tablets. Int J Pharm Pharm Sci 2014;6:198-204. 